REFERENCES:

[1] Nikiphorou E et al. Arthritis Res Ther 2016;18:251

[2] Ferreira RJO et al. Ann Rheum Dis 2019;78:e109.

Table 1. Associations of PGA in early RA at different time points

\begin{tabular}{cccccccccc}
\hline & 0 months & & 6 months & & 12 months & & 24 months & \\
\hline & $r(95 \% \mathrm{Cl})$ & $\mathrm{p}$ & $\mathrm{r}(95 \% \mathrm{Cl})$ & $\mathrm{p}$ & $\mathrm{r}(95 \% \mathrm{Cl})$ & $\mathrm{p}$ & $\mathrm{r}(95 \% \mathrm{Cl})$ & $\mathrm{p}$ \\
\hline VAS & 0.74 & $<0.001$ & 0.83 & $<0.001$ & 0.84 & $<0.001$ & 0.83 & $<0.001$ \\
pain & $(0.70-0.77)$ & & $(0.80-0.86)$ & & $(0.80-0.86)$ & & $(0.79-0.87)$ & \\
HAQ & 0.47 & $<0.001$ & 0.54 & $<0.001$ & 0.57 & $<0.001$ & 0.50 & $<0.001$ \\
& $(0.41-0.54)$ & & $(0.46-0.62)$ & & $(0.50-0.63)$ & & $(0.41-0.59)$ & \\
SJC28 & 0.27 & $<0.001$ & 0.27 & $<0.001$ & 0.21 & $<0.001$ & 0.23 & $<0.001$ \\
& $(0.19-0.35)$ & & $(0.18-0.35)$ & & $(0.12-0.30)$ & & $(0.13-0.33)$ & \\
TJC28 & 0.34 & $<0.001$ & 0.39 & $<0.001$ & 0.39 & $<0.001$ & 0.30 & $<0.001$ \\
& $(0.27-0.41)$ & & $(0.31-0.47)$ & & $(0.30-0.46)$ & & $(0.20-0.40)$ & \\
CRP & 0.08 & 0.05 & 0.09 & 0.07 & 0.19 & $<0.001$ & 0.03 & 0.63 \\
& $(0.00-0.17)$ & & $(0.00-0.19)$ & & $(0.10-0.28)$ & & $(0.09-0.14)$ & \\
& $\beta$ stand & $p$ & $\beta$ stand & $p$ & $\beta$ stand & $p$ & $\beta$ stand & $p$ \\
VAS & 0.66 & $<0.001$ & 0.76 & $<0.001$ & 0.74 & $<0.001$ & 0.80 & $<0.001$ \\
pain & & & & & & & & \\
HAQ & 0.20 & $<0.001$ & 0.18 & 0.01 & 0.20 & 0.03 & 0.22 & 0.003 \\
SJC28 & 0.17 & 0.03 & 0.15 & 0.04 & 0.11 & 0.04 & -- & -- \\
TJC28 & -- & -- & -- & -- & -- & -- & -- & - \\
CRP & -- & -- & -- & -- & -- & -- & & \\
\hline
\end{tabular}

Acknowledgements: I have no acknowledgements to declare.

Disclosure of Interests: Ludovico De Stefano: None declared, Serena Bugatti Speakers bureau: BMS, Lilly, Sanofi, Pfizer, Galapagos, Bernardo D'Onofrio: None declared, Ennio Favalli Speakers bureau: AbbVie, MSD, Novartis, Pfizer, UCB Pharma, Antonio Manzo: None declared, Roberto Caporali Speakers bureau: AbbVie, BMS, Celgene, HSD, Lilly, Pfizer, Roche, UCB Pharma, Carlomaurizio Montecucco Speakers bureau: BMS, Lilly, Sanofi, Pfizer, Galapagos, Roche, Novartis

DOI: 10.1136/annrheumdis-2021-eular.3653

\section{POS0576 EFFECTS OF ACUTE EXERCISE ON SERUM BDNF LEVEL IN PATIENTS WITH RHEUMATOID ARTHRITIS}

S. Baglan Yentur ${ }^{1}$, Z. Ercan ${ }^{1}$, G. Deniz ${ }^{2}$, A. Karatas ${ }^{3}$, M. Gur ${ }^{3}$, G. Alkan ${ }^{4}$, S. S. Koca ${ }^{3}{ }^{1}$ Firat University Faculty of Health Sciences, Department of Physiotherapy and Rehabilitation, Elazig, Turkey; ${ }^{2}$ Firat University School of Medicine, Department of Anatomy, Elazig, Turkey; ${ }^{3}$ Firat University School of Medicine, Department of Rheumatology, Elazig, Turkey; ${ }^{4}$ Firat University School of Medicine, Department of Physical Therapy and Rehabilitation, Elazig, Turkey

Background: Brain derived neurotrophic factor (BDNF) is a neurotrofic factor that may show healing, survival-promoting and protective effects on neurons in central and peripheral nervous system. The effect of physical exercise on serum BDNF is unclear. Also, BDNF level was found significantly lower in rheumatoid Arthritis (RA) patients with depression.

Objectives: Aim of this study is to investigate the variation of BDNF levels following acute exercise and potential correlation between BDNF levels and depression.

Methods: This study included 44 RA patients and 44 age and sex matched healthy controls ( $\mathrm{HC})$. Aerobic exercise was performed to all participants for a single session. The intervention was performed on a treadmill and included 5 minutes of warm-up, 20 minutes of walking exercise reaching at $60-80 \%$ of Maximal heart rate and 5 minutes of cool-down. Depression and anxiety levels were evaluated with Beck Depression Inventory (BDI) and Hospital Anxiety and Depression Scale (HADS). Blood samples from all subjects were taken and centrifuged before and immediately after the exercise intervention.

Results: Serum BDNF levels (both baseline and post-exercise) were similar in the RA and HC group (Table 1). Although after aerobic exercise serum BDNF levels were significantly decreased in both RA and HC groups (Wilcoxon Rank $\mathrm{P}<0.05) \triangle \mathrm{BDNF}$ levels was significantly higher in the RA group than $\mathrm{HC}$ group. Serum BDNF level was increased in $30.2 \%$ of healthy subjects and $4.5 \%$ of RA patients $(P=0.002)$. On the other hand, BDI, HADS depression and HADS anxiety indices were correlated significantly with $\triangle B D N F$ levels in the RA group $(\mathrm{p}<0.05)$ but not in $\mathrm{HC}$ group.

Conclusion: A single bout of exercise may be effective on serum BDNF levels in patients with RA and healthy subjects. However, psychological comorbidities affect the amelioration of BDNF level, in RA. The long-term effect of alterations on BDF level is candidate to evaluate by prospective studies.
Table 1. Clinical and laboratory characteristics in the study groups

\begin{tabular}{lccc}
\hline & $\mathrm{RA}(\mathrm{n}=44)$ & $\mathrm{HC}(\mathrm{n}=44)$ & $\mathrm{P}$ \\
\hline Mean age, years & $46.8 \pm 10.3$ & $43.4 \pm 6.4$ & $0.071^{\star}$ \\
Females, $\mathrm{n}(\%)$ & $32(72.7)$ & $31(70.5)$ & $0.813^{\star \star}$ \\
Active smokers, $\mathrm{n}(\%)$ & $12(27.3)$ & $10(22.7)$ & $0.622^{\star \star}$ \\
BMI, kg/m & $26.8 \pm 4.6$ & $25.6 \pm 2.4$ & $0.127^{\star}$ \\
HADS Depression & $10.2 \pm 3.9$ & $2.2 \pm 2.1$ & $<0.001^{\star}$ \\
HADS Anxiety & $10.4 \pm 4.1$ & $2.4 \pm 2.1$ & $<0.001^{\star}$ \\
BDI & $17.9 \pm 8.1$ & $3.7 \pm 4.1$ & $<0.001^{\star}$ \\
BDNF (baseline), $\mathrm{pg} / \mathrm{ml}$ & $798.9 \pm 381.1$ & $688.7 \pm 469.9$ & $0.069^{\star \star \star}$ \\
BDNF (post-exercise), pg/ml & $469.5 \pm 193.5$ & $509.9 \pm 380.4$ & $0.593^{\star \star \star}$ \\
BDDNF, pg/ml & $329.5 \pm 258.4$ & $211.1 \pm 302.6$ & $0.047^{\star \star \star}$ \\
BDNF increased, $\mathrm{n}(\%)$ & $2(4.5)$ & $13(30.2)$ & $0.002^{\star \star}$ \\
\hline
\end{tabular}

$\mathrm{RA}$; rheumatoid arthritis, $\mathrm{HC}$; healthy control, BMI; body mass index, HADS; Hospital Anxiety and Depression Scale, BDI; Beck Depression Inventory, BDNF; brain derived neurotrophic factor*Student's $t$ test, ${ }^{\star \star}$ Chi square test and ${ }^{* \star *}$ Mann Whitney $U$ test

Disclosure of Interests: None declared

DOI: 10.1136/annrheumdis-2021-eular.3768

\section{POS0577 EVALUATION OF COPING STRATEGIES IN RHEUMATOID ARTHRITIS PATIENTS}

B. A. Hiba ${ }^{1}$, S. Meriem², S. Miladi',2, F. Alia ${ }^{2,2}$, S. Leila ${ }^{2}$, O. Kmar², S. Kassab², S. Chikili², K. Ben Abdelghani' ${ }^{2}$ A. Laatar ${ }^{2} .{ }^{1}$ Mongi Slim University Hospital, Rheumatology, Tunis, Tunisia; ${ }^{2}$ Mongi Slim University Hospital, Rheumatology, TUNIS, Tunisia

Background: Studies have shown that the association of pain, stiffness, disability, and social restrictions in rheumatoid arthritis (RA) patients induce a sig nificantly increased level of depressed mood and stress. The use of favorable coping strategies could lead to improve physical and psychological well-being. Objectives: To evaluate coping strategies of RA patients and their associations with health-related quality of life (HRQoL) outcomes.

Methods: A cross-sectional sample of patients with established RA was evaluated using measures of coping: the Brief-COPE (scores presented for the two overarching coping styles: Approach coping including active coping, emotional support, use of informational support, positive reframing, planning and acceptance, and Avoidant coping including self-distraction, denial, substance use, behavioral disengagement venting and self-blame), the HRQoL (Mental and Physical Components [MCS/ PCS] of the Short Form 12), and the Rheumatoid Arthritis Impact of Disease score (RAID]. Multiple linear regression analyses were performed to evaluate the associations between coping strategies and HRQoL outcomes.

Results: The study sample comprised 45 patients with a female predominance $(91.9 \%)$, and a mean age of $55.7 \pm 9.9$ years [38-77]. The median disease duration was 10 years [38-77]. The majority of patients $(82.8 \%)$ were positive for either rheumatoid factor or anti-CCP. Half of the patients were on biological disease-modifying antirheumatic drugs. Two active coping strategies were identified: Approach coping $(E=4.29)$ and Avoidant Coping $(E=3.86)$, which explained $40 \%$ of the total variance. Mean RAID was $4.8 \pm 1.6$, while the mean PCS and MCS were $31.9 \pm 9.4$ and $39.7 \pm 9.4$, respectively. Approach coping and avoidant coping were associated with PCS $(r=0.4, p=0.03),(r=0.3, p=0.008)$ respectively. However, no association was found between coping strategies and MCS or RAID ( $>>0.05)$. In the multivariate model, approach coping and avoidant coping were significant to explain lower disease-specific HRQoL (PCS) (Beta $=0.4, p=0.008)$, (Beta=0.3, $p=0.02$ ) respectively. Conclusion: Approach and avoidance are associated with lower disease-specific HRQoL (PCS) but not with lower disease-specific HRQoL (MCS). Doctors should not forget to help their patients developing adaptive coping strategies.

Disclosure of Interests: None declared

DOI: 10.1136/annrheumdis-2021-eular.3781

\section{POS0578 CORRELATION BETWEEN EXPRESSION LEVELS OF MIR-155 AND MIR-223 IN SYNOVIAL FLUID AND ULTRASOUND SCORES FOR ACTIVE SYNOVITIS IN RHEUMATOID ARTHRITIS PATIENTS}

R. Shumnalieva ${ }^{1}$, D. Kachakova ${ }^{2}$, R. Kaneva ${ }^{2}$, Z. Kolarov ${ }^{1}$, S. Monov ${ }^{1} .{ }^{1}$ Clinic of Rheumatology, Department of Rheumatology, Medical University-Sofia, Bulgaria, Sofia, Bulgaria; ${ }^{2}$ Molecular Medicine Center, Department of Medical Chemistry and Biochemistry, Medical University-Sofia, Bulgaria, Sofia, Bulgaria

Background: MicroRNAs (miRNAs) are a class of small, non-coding RNAs that negatively regulate gene expression at posttranscriptional level. In rheumatoid arthritis studies have shown that miRNA are differentially expressed systemically as well as locally in the inflamed joints $[1,2]$. The correlation between their systemic or local expression levels and scores for disease activity and progression in RA make them possible candidate for biomarkers in the clinical practice.

Objectives: To analyze the expression levels of miR-155 and miR-223 in synovial fluid (SF) from RA patients in regard to the ultrasound scores for disease activity. Methods: A total number of $48 \mathrm{RA}$ patients according to the 1987 ACR criteria were included in the study. Expression levels of miR-155 and miR-223 SF were determined by qPCR (SybrGreen technology) and compared to healthy controls (HCs). Relative changes of gene expression levels of the studied miRNAs were calculated by $2^{-\Delta \Delta C}$ method. Musculoskeletal ultrasound (MSUS) examination was performed by two 